\title{
Antifeedant and insecticidal effects of extracts from Melia azedarach fruits and Peumus boldus leaves on Xanthogaleruca luteola larvae
}

\author{
Ítalo Chiffelle ${ }^{1}$, Amanda Huerta² ${ }^{\text {, Valentina Bobadilla² }}$, Gonzalo Macuada ${ }^{2}$, Jaime E. Araya ${ }^{1}$, \\ Tomislav Curkovic ${ }^{1}$, and Ricardo Ceballos $^{3^{*}}$ \\ ${ }^{1}$ Universidad de Chile, Facultad de Ciencias Agronómicas, Av. Santa Rosa 11315, Santiago, Chile. \\ ${ }^{2}$ Universidad de Chile, Facultad de Ciencias Forestales y de la Conservación de la Naturaleza, Av. Santa Rosa 11315, Santiago, Chile. \\ ${ }^{3}$ Instituto de Investigaciones Agropecuarias, INIA Quilamapu, Av. Vicente Méndez 515, Chillán, Chile. \\ "Corresponding author (rceballos@inia.cl).
}

Received: 16 April 2019; Accepted: 1 August 2019; doi:10.4067/S0718-58392019000400609

\begin{abstract}
Xanthogaleruca luteola (Coleoptera: Chrysomelidae) is an aggressive defoliating pest on elms (Ulmus sp.) worldwide. We evaluated the antifeedant and insecticidal effects of ethanolic and aqueous extracts from Melia azedarach L. green fruits and leaves of Peumus boldus Molina, on X. luteola third instar larvae, the most harmful stage. Five doses of the extracts were applied to fresh elm leaves to determine antifeedant effect evaluating consumed foliar area at $24 \mathrm{~h}$. Insecticidal activity was assessed through daily mortality for $14 \mathrm{~d}$. For each extract an antifeedant index, relative to respective control, and mean lethal concentrations $\left(\mathrm{LC}_{50}\right)$ were calculated. We found a direct relationship between concentration and both antifeedant and insecticidal effects for all extracts. A dose of $6.1 \% \mathrm{w} / \mathrm{v}$ of ethanolic extract of $M$. azedarach green fruits significantly inhibited larvae feeding behavior by $91 \%$ with a $\mathrm{LC}_{50} 1.49 \%$ at day 8 . On the other hand, $3.4 \%$ w/v of ethanolic extract of $P$. boldus inhibited larvae feeding behavior by $81 \%$ and $\mathrm{LC}_{50}$ at day 8 was $0.92 \% \mathrm{w} / \mathrm{v}$. All extracts showed insecticidal effect on X. luteola larvae, and the highest mortalities observed were $79 \%$ and $71 \%$ with ethanolic and aqueous extracts of $P$. boldus, respectively. Antifeedant and insecticidal effects observed with $M$. azedarach green fruits and $P$. boldus leaf extracts on X. luteola third instar larvae, support the development of botanical insecticides from both tree species in order to contribute to its integrated management.
\end{abstract}

Key words: Antifeedant effects, insecticidal effects, Melia azedarach, Peumus boldus, Xanthogaleruca luteola.

\section{INTRODUCTION}

The elm leaf beetle, Xanthogaleruca luteola Müller (Coleoptera: Chrysomelidae), is an insect distributed throughout Europe, North Africa, North and South America, Asia and Australia, being a severe defoliating pest of elms (Ulmus spp., Ulmaceae) worldwide (Borowiec and Sekerka, 2010; Vatanparast et al., 2012; Lefoe et al., 2014). Larvae live for 2 to $4 \mathrm{wk}$, having three instars (Huerta et al., 2011), and cause more damage than adults by skeletonizing the leaves. Severe infestations can cause complete defoliation of trees (Soudi and Moharramipour, 2011).

An efficient method for the reduction of pests, and the most used since the 1940s, has been the use of synthetic insecticides (Boulogne et al., 2012; Ortiz et al., 2012). This control is feasible because it is quick, easy to apply, and initially relatively cheap (Mahajan et al., 2009). However, it causes negative consequences on sustainability, environmental quality, and human health by generating toxic residues; insecticides also affect soil and water quality, non-target species, and induce pest resistance (Khaliq et al., 2012). In order to reduce these effects, new chemical control methods have been developed through the use of organic natural components (e.g. botanical insecticides) based on extracts of leaves, fruits, 
or other structures from plant species, with different results according to the species under study. This type of compounds has positive properties such as biodegradability, reduction of pest resistance, less impact on natural enemies, among others (Huerta et al., 2010; Amri et al., 2013).

Plants produce secondary metabolites, such as terpenes, alkaloids, rotenones, flavonoids (Amri et al., 2013), which produce antifeedant effects, interfere in the development or behavior of the insect, and block vital processes, and can thus contribute to the regulation of their populations (Pugazhvendan et al., 2009). In X. luteola, leaf extracts of tree species such as chinaberry, Melia azedarach L. (Meliaceae); pepper, Schinus molle L. (Anacardiaceae); and boldo, Peumus boldus Molina (Monimiaceae) have been tested on adults, showing promissory results (Huerta et al., 2010; Chiffelle et al., 2011a; 2011b; 2013). Melia azedarach is native to Iran, India, and China (Sharma and Paul, 2013). In Chile this tree is commonly found in urban areas, particularly used as an ornamental species in streets and parks. This species has become the object of studies to evaluate its useful properties, as extracts from different plant structures, in particular insecticide, antiviral, antioxidant, bactericide, and antiparasitic activities (Ahmed et al., 2008; Sen and Batra, 2012). The insecticidal activity of $M$. azedarach is found on extracts coming from leaves, fruits, and seeds, and it is assigned to a group of biologically active triterpenoids that have antifeeding effects (Isman, 2002). Green fruits have shown greater toxicity than mature ones on insect species as Drosophila melanogaster Meigen (Diptera: Drosophilidae) (Huerta et al., 2008). Xanthogaleruca luteola adults exposed to green fruit extracts obtained from M. azedarach, using either water or ethanol as solvents, showed adulticidal activity; ethanolic extract was more effective with a mean lethal concentration $\left(\mathrm{LC}_{50}\right)$ of $0.9 \%$ at day 3 after exposure (Chiffelle et al., 2011a). Likewise, P. boldus, an endemic tree species of the Chilean sclerophyllous forest (Verdeguer et al., 2011; Vogel et al., 2011) has also been tested for its insecticidal and fungicidal properties (Bustos-Figueroa et al., 2009; Alpsoy, 2010) and antifeedant effect (Silva et al., 2013). Chiffelle et al. (2011b) evaluated the toxicity of extracts from new and mature leaves of P. boldus in X. luteola adults, showing up $97 \%$ mortality; the same report estimated a $\mathrm{LC}_{50}$ of $1.2 \% \mathrm{w} / \mathrm{v}, 2 \mathrm{~d}$ after exposure. There are no reports on the activity from these extracts, neither M. azedarach nor P. boldus on X. luteola larvae, considered the most harmful stage on elms (Soudi and Moharramipour, 2011). We hypothesized that extracts from M. azaderach green fruits and $P$. boldus leaves have antifeedant and insecticidal activity on the X. luteola third instar larvae, and the physiological age of $P$. boldus leaves modifies this activity. Our objective was to evaluate the antifeedant and insecticidal effects of ethanolic and aqueous extracts obtained from M. azedarach green fruits and P. boldus leaves (new and mature) on X. luteola third instar larvae.

\section{MATERIALS AND METHODS}

\section{Plant material and extracts preparation}

Melia azedarach L. green fruits were collected from mature trees ( $>30$-yr-old) located in Antumapu Campus, College of Forest and Nature Conservation Sciences, whereas Peumus boldus Molina, either mature or new leaves, as described by Chiffelle et al. (2011b), were collected from mature trees located at the College of Veterinary and Livestock Medicine,

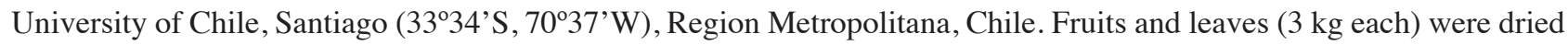
in a forced air oven (Mod. 18, Thelco, Englewood, Colorado, USA) at $40{ }^{\circ} \mathrm{C}$ until constant weight, and afterwards grinded in a mechanical grain mill to obtain powdered material. Increasing volumes of either distilled water or $96 \%$ ethanol (Merck, Darmstadt, Germany) were added to the milled material to obtain a two phases liquid-solid mixture. Then, this mixture was stirred with a magnetic stirrer (Heidolph, MR $3001 \mathrm{~K}$, Schwabach, Germany), at $37{ }^{\circ} \mathrm{C}$ the first hour, and at room temperature to complete $24 \mathrm{~h}$. Subsequently, the homogenized mixture was filtered through a Whatman $\mathrm{N}^{\circ} 1$ filter paper and centrifuged for $15 \mathrm{~min}$ at $1500 \mathrm{rpm}$ to obtain the supernatant (extracts). In order to calculate maximum concentration (mc) of total solids, $15 \mathrm{~mL}$ of each extract were dried until constant weight at $100{ }^{\circ} \mathrm{C}$ in a forced air oven. Five doses of ethanolic and aqueous extracts were prepared starting from the respective mc (M. azedarach green fruits and P. boldus new and mature leaves) (Tables 1 and 2).

\section{Insects' rearing}

First larval stages of $X$. luteola were collected in La Florida, Santiago, Metropolitan Region, Central Chile, from infested elm trees during the summer season, and taken to the Forest Entomology Laboratory, Faculty of Forestry and Nature Conservation Sciences, University of Chile. Larvae were transferred into Petri dishes (10 cm diameter) lined with slightly 
wet filter paper, and fed ad libitum with fresh washed elm leaves in an incubator at $20 \pm 3{ }^{\circ} \mathrm{C}, 60 \pm 6 \% \mathrm{RH}$, and photoperiod of 14:10 h until they reached the third instar (Huerta et al., 2011).

Table 1. Foliar area consumed and antifeedant effect (\%; mean \pm standard error) of ethanolic and aqueous extracts from green fruits of Melia azedarach, and mature and new leaves of Peumus boldus on Xanthogaleruca luteola third instar larvae, at different doses after $24 \mathrm{~h}$.

\begin{tabular}{|c|c|c|c|c|c|c|c|}
\hline \multicolumn{4}{|c|}{ Ethanolic extract } & \multicolumn{4}{|c|}{ Aqueous extract } \\
\hline \multirow[b]{2}{*}{ Dose } & \multicolumn{2}{|c|}{ Foliar area consumed } & \multirow{2}{*}{$\underset{\text { effect }^{\S}}{\text { Antifeedant }}$} & \multirow[b]{2}{*}{ Dose } & \multicolumn{2}{|c|}{ Foliar area consumed } & \multirow{2}{*}{$\begin{array}{l}\text { Antifeedant } \\
\text { effect }\end{array}$} \\
\hline & Control & Treated & & & Control & Treated & \\
\hline$\% \mathrm{w} / \mathrm{v}$ & \multicolumn{3}{|c|}{$\longrightarrow \%$} & $\% \mathrm{w} / \mathrm{v}$ & \multicolumn{3}{|c|}{ 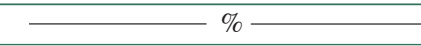 } \\
\hline \multicolumn{8}{|c|}{ M. azedarach green fruit } \\
\hline 6.1 & 1.83 & $0.15^{*}$ & $91 \pm 1 b$ & 5.7 & 1.67 & $0.29 *$ & $85 \pm 1 b$ \\
\hline 4.7 & 1.70 & 0.19 & $87 \pm 1 b$ & 4.4 & 1.35 & $0.39 *$ & $68 \pm 1 \mathrm{ab}$ \\
\hline 3.0 & 1.05 & 0.23 & $79 \pm 1 \mathrm{ab}$ & 3.0 & 1.23 & $0.42 *$ & $63 \pm 1 a b$ \\
\hline 2.4 & 0.88 & 0.38 & $56 \pm 2 \mathrm{ab}$ & 2.4 & 1.36 & 0.82 & $54 \pm 2 a$ \\
\hline 1.2 & 0.87 & 0.39 & $32 \pm 2 \mathrm{a}$ & 1.2 & 1.57 & 1.52 & $35 \pm 2 \mathrm{a}$ \\
\hline \multicolumn{8}{|c|}{ P. boldus new leaves } \\
\hline 3.4 & 0.85 & $0.21 *$ & $81 \pm 2 b$ & 6.3 & 0.79 & $0.18^{*}$ & $74 \pm 0 b$ \\
\hline 2.5 & 1.00 & $0.36^{*}$ & $70 \pm 1 a b$ & 4.8 & 0.86 & 0.49 & $47 \pm 1 \mathrm{ab}$ \\
\hline 1.6 & 1.07 & 0.51 & $56 \pm 1 \mathrm{ab}$ & 3.2 & 1.19 & 0.87 & $31 \pm 0 \mathrm{a}$ \\
\hline 1.3 & 0.86 & 0.39 & $54 \pm 1 \mathrm{ab}$ & 2.5 & 1.20 & 0.89 & $26 \pm 0 \mathrm{a}$ \\
\hline 0.7 & 1.53 & 1.12 & $31 \pm 0 \mathrm{a}$ & 1.3 & 1.34 & 1.22 & $12 \pm 0 \mathrm{a}$ \\
\hline \multicolumn{8}{|c|}{ P. boldus mature leaves } \\
\hline 9.1 & 0.84 & $0.04 *$ & $95 \pm 0 b$ & 2.9 & 1.31 & $0.68^{*}$ & $49 \pm 0 a$ \\
\hline 6.8 & 1.11 & $0.32 *$ & $71 \pm 1 \mathrm{ab}$ & 2.2 & 0.99 & $0.56^{*}$ & $40 \pm 1 \mathrm{a}$ \\
\hline 4.5 & 1.42 & $0.65 *$ & $57 \pm 0 \mathrm{ab}$ & 1.5 & 1.09 & 0.80 & $32 \pm 1 a$ \\
\hline 3.6 & 1.54 & $0.69 *$ & $55 \pm 1 \mathrm{a}$ & 1.2 & 1.23 & 1.05 & $24 \pm 0 \mathrm{a}$ \\
\hline 1.8 & 1.48 & 1.05 & $30 \pm 0 \mathrm{a}$ & 0.6 & 1.44 & 1.29 & $14 \pm 0 \mathrm{a}$ \\
\hline
\end{tabular}

*Significant differences between control and extract for each dose according to Wilcoxon's test $(\mathrm{P}<0.05)$. ${ }^{\S}$ Means sharing a letter, for each extract, do not differ significantly according Tukey's test $(\mathrm{P}<0.05)$.

Table 2. Mortality $(\% \pm \mathrm{SE})$ of Xanthogaleruca luteola third instar larvae after exposure to different doses of ethanolic and aqueous extracts from Melia azedarach green fruit (evaluated at day 7) and new (at day 8) and mature (at day 9) leaves of Peumus boldus.

\begin{tabular}{|c|c|c|c|c|c|}
\hline \multicolumn{2}{|c|}{ M. azedarach green fruits } & \multicolumn{2}{|c|}{ P. boldus new leaves } & \multicolumn{2}{|c|}{ P. boldus mature leaves } \\
\hline Dose & Mortality & Dose & Mortality & Dose & Mortality \\
\hline$\% \mathrm{w} / \mathrm{v}$ & $\%$ & $\% \mathrm{w} / \mathrm{v}$ & $\%$ & $\% \mathrm{w} / \mathrm{v}$ & $\%$ \\
\hline \multicolumn{6}{|c|}{ Ethanolic extract } \\
\hline 4.7 & $60 \pm 1 \mathrm{~d}$ & 3.4 & $79 \pm 3 d$ & 9.1 & $74 \pm 4 c$ \\
\hline 3.0 & $54 \pm 2 c$ & 2.5 & $66 \pm 0 c$ & 6.8 & $65 \pm 3 b c$ \\
\hline 2.4 & $44 \pm 2 b$ & 1.6 & $58 \pm 0 \mathrm{~b}$ & 4.5 & $61 \pm 3 b$ \\
\hline 1.5 & $44 \pm 1 b$ & 1.3 & $58 \pm 3 b$ & 3.6 & $52 \pm 4 a$ \\
\hline 1.2 & $26 \pm 3 \mathrm{a}$ & 0.7 & $45 \pm 3 \mathrm{a}$ & 1.8 & $48 \pm 4 \mathrm{a}$ \\
\hline \multicolumn{6}{|c|}{ Aqueous extract } \\
\hline 4.4 & $63 \pm 2 d$ & 6.3 & $71 \pm 4 c$ & 2.9 & $54 \pm 3 \mathrm{cc}$ \\
\hline 3.0 & $52 \pm 2 c$ & 4.8 & $71 \pm 4 c$ & 2.2 & $50 \pm 4 \mathrm{c}$ \\
\hline 2.4 & $44 \pm 2 b$ & 3.2 & $54 \pm 3 b c$ & 1.5 & $50 \pm 4 c$ \\
\hline 1.5 & $30 \pm 1 \mathrm{a}$ & 2.5 & $50 \pm 4 b$ & 1.2 & $42 \pm 3 b$ \\
\hline 1.2 & $26 \pm 2 \mathrm{a}$ & 1.3 & $46 \pm 4 \mathrm{a}$ & 0.6 & $33 \pm 3 a$ \\
\hline
\end{tabular}

Means sharing a letter, for each extract, do not differ significantly according Tukey's test $(\mathrm{P}<0.05)$.

Mortalities values were corrected according to Abbott procedure. 


\section{Antifeedant effect}

Fresh elm leaves (similar in size) were immersed for $30 \mathrm{~s}$ in each extract, followed by a $30 \mathrm{~s}$ period for solvent evaporation, and water or ethanol were used as appropriated controls. Inside a Petri dish two leaves (treated and control) along with two third instar larvae were incubated for $24 \mathrm{~h}$, as described previously. Five replicates were carried out and the consumed foliar area was determined by the ImageJ program (Schneider et al., 2012). The antifeedant effect was estimated as ( 1 $T / C) \times 100$, where $T$ and $C$ correspond to the areas consumed in treated and control leaves, respectively. Foliar consumed area was analyzed through the Wilcoxon ranks test $(\mathrm{P}<0.05)$ and the antifeedant effect data were submitted to the ANOVA procedure $(\mathrm{P}<0.05)$ followed by Tukey' test to compare between doses $(\mathrm{P}<0.05)$.

\section{Insecticidal effect and mean lethal concentration}

Five doses of each extracts, as described previously, were evaluated on X. luteola larvae (III instar) using two fresh leaves of Ulmus sp., previously immersed in the extract or control (solvent) following the procedure describe above. Mortality of $X$. luteola larvae was evaluated daily for $14 \mathrm{~d}$, and data were submitted to ANOVA followed by Tukey test for multiple comparisons between doses $(\mathrm{P}<0.05)$. In order to obtain the mean lethal concentration $\left(\mathrm{LC}_{50}\right)$ for each extract, we conducted Probit analysis and mortalities values were corrected according to Abbott procedure (Abbott, 1925).

\section{RESULTS}

\section{Antifeedant effect}

Feeding behavior of $X$. luteola third instar larvae was significantly inhibited by ethanolic $\left(\mathrm{F}_{4,20}=3.84, \mathrm{P}=0.018\right)$ and aqueous $\left(\mathrm{F}_{4,20}=4.65, \mathrm{P}=0.008\right)$ extracts from $M$. azedarach green fruits (Table 1$)$. From $2.4 \% \mathrm{w} / \mathrm{v}$ and above the antifeedant effect was greater than $50 \%$ for both ethanolic and aqueous extracts. At $6.1 \% \mathrm{w} / \mathrm{v}$ ethanolic extract, the feeding behavior was inhibited by $91 \%$ and $85 \%$ by the aqueous extract of green fruits at $5.7 \% \mathrm{w} / \mathrm{v}$.

Ethanolic extracts of new and mature leaves of $P$. boldus caused a significant $\left(\mathrm{F}_{4,20}=2.99, \mathrm{P}=0.044\right)$ antifeedant effect larger than 50\%, except at the lowest dose. On the other hand, the antifeedant effect did not exceed 50\% when we apply aqueous extracts of new or mature leaves of $P$. boldus, except at $6.3 \% \mathrm{w} / \mathrm{v}$ of new leaves extract (Table 1 ). Ethanolic extract from new leaves of $P$. boldus significantly $(\mathrm{P}<0.05)$ inhibited by $81 \%$ and $70 \%$ feeding of larvae at concentrations of $3.4 \%$ and $2.5 \% \mathrm{w} / \mathrm{v}$, respectively. Ethanolic extract from mature leaves of $P$. boldus showed the highest and significant $\left(\mathrm{F}_{4,20}=8.95, \mathrm{P}=0.003\right)$ antifeeding activity on $X$. luteola larvae, ranging from $96 \%$ at $9.1 \% \mathrm{w} / \mathrm{v}$ to $55 \%$ at $3.6 \% \mathrm{w} / \mathrm{v}$. A significantly lower area consumed by larvae was observed in all doses of the extract of mature leaves, except at $1.8 \% \mathrm{w} / \mathrm{v}$. Similarly, the aqueous extract of new leaves showed a significant $\left(\mathrm{F}_{4,20}=6.63, \mathrm{P}=0.001\right)$ antifeedant effect, ranging from $74 \%$ and $12 \%$. On the other hand, mature leaves aqueous extract provided significantly lower leaf area consumed only at $2.9 \%$ and $2.2 \% \mathrm{w} / \mathrm{v}$, and the antifeedant effect of the mature leaves aqueous extract did not reached $50 \%\left(\mathrm{~F}_{4,20}=2.33, \mathrm{P}=0.096\right)$.

\section{Insecticidal effect and mean lethal concentration}

We observed a significant insecticidal activity on $X$. luteola larvae whit ethanolic $\left(\mathrm{F}_{5,24}=8.21, \mathrm{P}<0.001\right)$ and aqueous $\left(\mathrm{F}_{5,24}=5.04, \mathrm{P}=0.003\right)$ extracts of $M$. azedarach green fruits. The observed mortalities were $60 \%$ and $63 \%$ for the highest doses of ethanolic and aqueous extract, respectively (Table 2). The $\mathrm{LC}_{50}$ at day 8 for the ethanolic extract was $1.49 \% \mathrm{w} / \mathrm{v}$, whereas it was $1.87 \% \mathrm{w} / \mathrm{v}$ for the aqueous extract (Table 3).

The new leaves ethanolic extract of $P$. boldus showed significant $\left(\mathrm{F}_{5,24}=135.78, \mathrm{P}<0.001\right)$ insecticidal activity. After $8 \mathrm{~d}$ of exposure we observed $79 \%$ of mortality at $3.4 \% \mathrm{w} / \mathrm{v}$ and $45 \%$ at $0.7 \% \mathrm{w} / \mathrm{v}$, and the $\mathrm{LC}_{50} \mathrm{was} 0.92 \% \mathrm{w} / \mathrm{v}$ (Table 2). Analogously, the aqueous extract of new leaves significantly $\left(\mathrm{F}_{5,24}=15.20, \mathrm{P}<0.001\right)$ presented insecticidal activity, mortalities observed at day 8 were $71 \%$ at $6.3 \% \mathrm{w} / \mathrm{v}$ and $46 \%$ at $1.3 \% \mathrm{w} / \mathrm{v}$, and $\mathrm{LC}_{50}$ was $3.26 \% \mathrm{w} / \mathrm{v}$. Ethanolic $\left(\mathrm{F}_{5,59}=\right.$ $92.84, \mathrm{P}<0.05)$ and aqueous $\left(\mathrm{F}_{5,24}=52.68, \mathrm{P}<0.001\right)$ extracts, from mature leaves, caused $74 \%$ and $54 \%$ of mortality at $9.1 \% \mathrm{w} / \mathrm{v}$ and $2.9 \% \mathrm{w} / \mathrm{v}$, respectively. The $\mathrm{LC}_{50}$ after $8 \mathrm{~d}$ of exposure were $1.20 \%$ for ethanolic extract and $3.26 \% \mathrm{w} / \mathrm{v}$ for the aqueous extract. 
Table 3. Median lethal concentration $\left(\mathrm{LC}_{50}\right)$ and parameters of Probit regression for ethanolic and aqueous extracts from Melia azedarach (green fruits) and Peumus boldus leaves (new and mature) on Xanthogaleruca luteola third instar larvae at different evaluation times.

\begin{tabular}{|c|c|c|c|c|c|c|}
\hline \multirow[b]{2}{*}{ Time } & \multicolumn{2}{|c|}{ Ethanolic extract } & \multirow[b]{2}{*}{ Chi-square $^{1}$} & \multicolumn{2}{|c|}{ Aqueous extract } & \multirow[b]{2}{*}{ Chi-square' } \\
\hline & Slope & $\mathrm{LC}_{50}$ & & Slope & $\mathrm{LC}_{50}$ & \\
\hline $\mathrm{d}$ & mean $\pm \mathrm{SE}$ & $\% \mathrm{w} / \mathrm{v}$ & & mean $\pm \mathrm{SE}$ & $\% \mathrm{w} / \mathrm{v}$ & \\
\hline \multicolumn{7}{|c|}{ M. azedarach green fruits } \\
\hline 7 & $19 \pm 4$ & 1.96 & 7.71 & $20 \pm 2$ & 2.61 & 8.65 \\
\hline 8 & $21 \pm 3$ & 1.49 & 7.42 & $18 \pm 2$ & 1.87 & 6.19 \\
\hline 9 & $16 \pm 2$ & 0.83 & 6.39 & $15 \pm 1$ & 1.27 & 5.23 \\
\hline \multicolumn{7}{|c|}{ P. boldus new leaves } \\
\hline 7 & $15 \pm 4$ & 1.11 & 1.86 & $18 \pm 5$ & 3.70 & 2.95 \\
\hline 8 & $21 \pm 2$ & 0.92 & 2.77 & $20 \pm 4$ & 2.09 & 2.96 \\
\hline \multicolumn{7}{|c|}{ P. boldus mature leaves } \\
\hline 8 & $16 \pm 2$ & 1.20 & 2.25 & $8 \pm 4$ & 3.26 & 1.82 \\
\hline 9 & $15 \pm 1$ & 1.00 & 2.51 & $13 \pm 2$ & 1.72 & 2.61 \\
\hline
\end{tabular}

${ }^{1}$ Goodness of fit for Probit model, critical Chi-square value $11.07(\mathrm{df}=5 ; \mathrm{p} \leq 0.05)$ and $9.45(\mathrm{df}=4 ; \mathrm{p} \leq 0.05)$ for green fruit and leaf extracts.

\section{DISCUSSION}

As far as we know, there are no reports on the antifeedant and insecticidal effects from M. azedarach and P. boldus extracts on X. luteola larvae. All previous reports evaluated extracts on X. luteola adults. Defagó et al. (2006) found 100\% antifeedant effect when ethanolic extracts from M. azedarach fruits at $5 \% \mathrm{w} / \mathrm{v}$ were tested on adults. Similarly, Chiffelle et al. (2011a) found $100 \%$ antifeedant effect on adults at $3.6 \% \mathrm{w} / \mathrm{v}$ of M. azedarach extract. We observed $91 \%$ antifeedant effect when the ethanolic extract from M. azedarach green fruits was tested at $6.1 \% \mathrm{w} / \mathrm{v}$ on X. luteola larvae, the most harmful stage, suggesting these types of extracts are more effective in reducing elm feeding by adults. In X. luteola adults, aqueous extracts from leaves (new and mature processed together) of $S$. molle yielded $98.3 \%$ antifeedant effect using $2.5 \% \mathrm{w} / \mathrm{v}$ (Huerta et al., 2010). The reduction in leaf consumption indicate the ability of larvae to discriminated between treated and untreated leaves, resulting in lower intake of treated leaves with M. azedarach green fruit extracts compared to control. We found a direct and positive relationship between extract concentration and antifeedant effect. These effects vary depending on the plant component (e.g. fruits, leaves, etc.) and target species, and it could be attributed to the direct antifeedant effect or post-ingestion effects (Isman, 2002).

On the other hand, antifeedant effects on $X$. luteola larvae have been reported using extracts from other plant species. Shekari et al. (2008) reported 90\%, 100\%, and 100\% antifeedant effect using Artemisia annua L. (Asteraceae) methanolic extracts at $2.5 \%, 5 \%$ and $10 \% \mathrm{w} / \mathrm{v}$, respectively. Our results shown lower antifeedant effect using M. azedarah green fruit extracts at similar concentrations, suggesting greenfruit extracts have lower activity than A. annua extracts. Both aqueous and ethanolic extracts from new and mature leaves of $P$. boldus showed antifeedant activity on third instar larvae of $X$. luteola. The lowest degree of elm leaves consumed with the application of $P$. boldus ethanolic extract from mature leaves, was obtained at $9.1 \%$.

Antifeedant effects and insecticidal properties are assigned to secondary metabolites, as terpenoids present in the P. boldus leaves (Boulogne et al., 2012; Amri et al., 2013). However, we did not identify compounds present in extracts used in our experiments. At the same concentration, insecticidal activity was higher in P. boldus ethanolic extracts, probably due to the superior solubility in ethanol from secondary metabolites. These results differ from Defagó et al. (2006), who found up to $100 \%$ X. luteola mortality using ethanolic extracts at 5\%, but in adults, evaluated at $16 \mathrm{~d}$ after exposure. Using ethanolic and aqueous at $1.5 \% \mathrm{w} / \mathrm{v}$ or greater concentrations, we observed a direct relationship between doses and insecticidal activity of all extracts of $P$. boldus leaves. The ethanolic extract from new leaves at $3.4 \% \mathrm{w} / \mathrm{v}$ provided the greatest mortality $(79 \%)$ at $8 \mathrm{~d}$. The toxicity of ethanolic and aqueous extracts of new and mature $P$. boldus leaves had been evaluated previously in $X$. luteola adults, finding up to $82 \%$ mortality using both solvents at $5.7 \% \mathrm{w} / \mathrm{v}$ from new leaves, whereas mortality ranged from $81 \%$ (aqueous extract) to $68 \%$ (ethanolic) at $6.8 \% \mathrm{w} / \mathrm{v}, 2 \mathrm{~d}$ after exposure (Chiffelle et al., 2011b). These results agree with our data that show the greater effectiveness of ethanolic extracts from new leaves of P. boldus on X. luteola third instar larvae. 
Regarding the insecticidal activity, extracts from S. molle (leaves) (Huerta et al., 2010) and M. azedarach (green fruits) have been previously tested (Chiffelle et al., 2011a), reaching $87.5 \%$, and $86 \%$ to $76 \%$ mortalities respectively, using similar or lower concentrations (3.5\% w/v in S. molle and $2.4 \%$ in M. azedarach), and shorter evaluation times (4 d in $S$. molle), in comparison to our results.

The new leaves and, in general, the plant parts with annual growth have a higher concentration of secondary metabolites, which apparently do not have a direct function in the growth and development of plants, since a relationship between secondary metabolites and metabolic processes has not been found. In addition, new leaves do not use hardening as a defense mechanism due to their constant growth, which explain the store of more secondary metabolites or active compounds as a defense mechanism (Fang et al., 2016). In our study new leaves were more effective than mature leaves on mortality of $X$. luteola third larval instar. Our results using $M$. azedarach green fruit extracts, both ethanolic and aqueous, shown $X$. luteola larvae $\mathrm{LC}_{50}$ values decreased along with the evaluation time. The values at day 8 after exposure were $1.49 \% \mathrm{w} / \mathrm{v}$ (ethanolic extract) and $1.87 \% \mathrm{w} / \mathrm{v}$ (aqueous extract) whereas at day 7 were $1.96 \%$ and $2.61 \% \mathrm{w} / \mathrm{v}$, respectively. No previous reports on $\mathrm{LC}_{50}$ from $M$. azedarach green fruit extracts used on $X$. luteola larvae were found, however, mean lethal concentrations have been reported for adults. For instance, Chiffelle et al. (2011a) found $\mathrm{LC}_{50}$ values of $0.94 \% \mathrm{w} / \mathrm{v}$ (ethanolic extract evaluated at day 3) and 6.55\% w/v (aqueous at day 5), whereas Defagó et al. (2006) found an $\mathrm{LC}_{50}$ of $2 \% \mathrm{w} / \mathrm{v}$ at day 9 after exposure, suggesting the concentrations needed to kill $50 \%$ of the population are greater when targeting larvae. In our study, the ethanolic $P$. boldus leaf extracts showed lower $\mathrm{LC}_{50}$ than aqueous extracts at 8 day of evaluation on $X$. luteola third instar larvae. The lowest $\mathrm{LC}_{50}$ was $0.92 \% \mathrm{w} / \mathrm{v}$ using the ethanolic extract of new leaves. Chiffelle et al. (2011b) reported for X. luteola adults $\mathrm{LC}_{50}$ of $0.8 \%$ and $1.1 \% \mathrm{w} / \mathrm{v}$ using ethanolic extracts of new and mature leaves of $P$. boldus, respectively. Despite the similar $\mathrm{LC}_{50}$ values between studies, the evaluation on $X$. luteola adults was estimated at day 3 , whereas we did it as soon as at day 8 , suggesting the third larval instar is less susceptible to $P$. boldus extracts. Besides, a $\mathrm{LC}_{50}$ of $1.28 \% \mathrm{w} / \mathrm{v}$ at $7 \mathrm{~d}$ was estimated using $S$. molle new leaf ethanolic extract against $X$. luteola larvae (Chiffelle et al., 2013). Lower $\mathrm{LC}_{50}$, ranging from $0.3 \%$ to $0.63 \% \mathrm{v} / \mathrm{v}$, were found on $X$. luteola third larval instar exposed to essential oils obtained from leaves of the German thyme Thymus vulgaris $\mathrm{L}$. and the true lavender Lavandula angustifolia M. (Lamiaceae) at 1-d exposure (Khosravi and Sendi, 2013).

\section{CONCLUSIONS}

We found antifeedant and insecticidal effects from both Melia azedarach green fruits and Peumus boldus leaf extracts on the third instar larvae of Xanthogaleruca luteola. A direct and positive relationship between the concentration and the antifeedant effect, was observed. Both, the green fruits and the new and mature leaf ethanolic extracts, generated lower mean lethal concentration $\left(\mathrm{LC}_{50}\right)$ than the aqueous ones, but extracts from new P. boldus leaves were more active than the older ones. Besides, extracts from M. azedarach green fruits and $P$. boldus leaves were more effective for adults than larvae. Both $M$. azedarach and $P$. boldus extracts as botanical insecticides are promising tools to the integrated management of $X$. luteola third instar larvae.

\section{REFERENCES}

Abbott, W.S. 1925. A method of computing the effectiveness of an insecticide. Journal of Economic Entomology 18:265-267. doi.org/10.1093/jee/18.2.265a.

Ahmed, M.F., Ibrahim, M., Ahmed, M.A., Thayyil, H., and Zameeruddin, K. 2008. Antioxidative activity of Melia azedarach Linn leaf extract. Iranian Journal of Pharmacology and Therapeutics 7:31-30.

Alpsoy, L. 2010. Inhibitory effect of essential oil on aflatoxin activities. African Journal of Biotechnology 9:2474-2481.

Amri, I., Hamrouni, L., Hanana, M., and Jamoussi, B. 2013. Reviews on phytotoxic effects of essential oils and their individual components: news approach for weeds management. International Journal of Applied Biology and Pharmaceutical Technology 4:96-114.

Borowiec, L., and Sekerka, L. 2010. Cassidinae. Catalogue of Palearctic Coleoptera 6:64-65.

Boulogne, I., Petit, P., Ozier-Lafontaine, H., Desfontaines, L., and Loranger-Merciris, G. 2012. Insecticidal and antifungal chemicals produced by plants: a review. Environmental Chemistry Letters 10:325-347. doi:10.1007/s10311-012-0359-1.

Bustos-Figueroa, G., Osses-Ruiz, F., Silva-Aguayo, G., Tapia-Vargas, M., Hepp-Gallo, R., and Rodriguez-Maciel, J.C. 2009. Insecticidal properties of Peumus boldus Molina powder used alone and mixed with lime against Sitophilus zeamais Motschulsky (Coleoptera: Curculionidae). Chilean Journal of Agricultural Research 69:350355. doi:10.4067/S0718-58392009000300007. 
Chiffelle, I., Huerta, A., Azua, F., Puga, K., and Araya, J.E. 2011a. Antifeeding and insecticide properties of aqueous and ethanolic fruit extracts from Melia azedarach L. on the elm leaf beetle Xanthogaleruca luteola Muller. Chilean Journal of Agricultural Research 71:218-225. doi:10.4067/S0718-58392011000200006.

Chiffelle, I., Huerta, A., Celis, M., and Araya, J. 2013. Proximal analysis and insecticidal effects of extracts from pepper tree (Schinus molle) leaves on elm leaf beetle (Xanthogaleruca luteola) larvae. Industrial Crops and Products 43:523-528. doi:10.1016/j.indcrop.2012.07.062.

Chiffelle, I., Huerta, A., Jimenez, R., and Araya, J.E. 2011b. Proximal analysis and toxicity of extracts from young and mature leaves of the boldo tree (Peumus boldus) on elm leaf beetle (Xanthogaleruca luteola). Canadian Journal of Forest Research 41:2259-2266. doi:10.1139/X11-137.

Defagó, M., Valladares, G., Banchio, E., Carpinella, C., and Palacios, S. 2006. Insecticide and antifeedant activity of different plant parts of Melia azedarach on Xanthogaleruca luteola. Fitoterapia 77:500-505. doi:10.1016/j.fitote.2006.05.027.

Fang, Y., Mei, H., Zhou, B., Xiao, X., Yang, M., Huang, Y., et al. 2016. De novo transcriptome analysis reveals distinct defense mechanisms by young and mature leaves of Hevea brasiliensis (Para Rubber Tree). Scientific Reports 6:33151. doi:10.1038/srep33151.

Huerta, A., Chiffelle, I., Lizana, D., and Araya, J.E. 2008. Actividad insecticida de extractos del fruto de Melia azedarach en distintos estados de madurez sobre Drosophila melanogaster. Boletín de Sanidad Vegetal. Plagas 34:425-432.

Huerta, A., Chiffelle, I., Puga, K., Azúa, F., and Araya, J.E. 2010. Toxicity and repellence of aqueous and ethanolic extracts from Schinus molle on elm leaf beetle Xanthogaleruca luteola. Crop Protection 29:1118-1123. doi:10.1016/j.cropro.2010.04.010.

Huerta, A., Chiffelle, I., Puga, K., Azúa, F., Jimenez, R., and Araya, J. 2011. Life cycle of Xanthogaleruca luteola (Coleoptera: Chrysomelidae) in Santiago, Chile, and sex fenotype differentiation of adults. Boletín de Sanidad Vegetal. Plagas 37:57-64.

Isman, M. 2002. Insect antifeedants. Pesticide Outlook 13:152-157. doi:10.1039/B206507J.

Khaliq, A., Matloob, A., and Riaz, Y. 2012. Bio-economic and qualitative impact of reduced herbicide use in direct seeded fine rice through multipurpose tree water extracts. Chilean Journal of Agricultural Research 72:350. doi:10.4067/S0718-58392012000300008.

Khosravi, R., and Sendi, J.J. 2013. Toxicity, development and physiological effect of Thymus vulgaris and Lavandula angustifolia essential oils on Xanthogaleruca luteola (Coleoptera: Chrysomelidae). Journal of King Saud University - Science 25:349355. doi:10.1016/j.jksus.2013.01.002.

Lefoe, G., Dominiak, B., Worsley, P., and Davies, J. 2014. Elm leaf beetle Xanthogaleruca luteola (Muller) dispersal across south eastern Australia (1989-2011). Journal of Plant Protection Quarterly 29:61.

Mahajan, G., Chauhan, B.S., and Johnson, D.E. 2009. Weed management in aerobic rice in Northwestern Indo-Gangetic Plains. Journal of Crop Improvement 23:366-382. doi:10.1080/15427520902970458.

Ortiz, M., Silva, G., Tapia, M., Rodríguez, J.C., Lagunes, A., Santillán-Ortega, C., et al. 2012. Toxicity of boldo Peumus boldus Molina for Sitophilus zeamais Motschulsky and Tribolium castaneum Herbst. Chilean Journal of Agricultural Research 72:345-349. doi:10.4067/s0718-58392012000300007.

Pugazhvendan, S., Elumalai, K., Ross, P.R., and Soundarajan, M. 2009. Repellent activity of chosen plant species against Tribolium castaneum. World Journal of Zoology 4:188-190.

Schneider, C.A., Rasband, W.S., and Eliceiri, K.W. 2012. NIH Image to ImageJ: 25 years of image analysis. Nature Methods 9:671-675. doi:10.1038/nmeth.2089.

Sen, A., and Batra, A. 2012. Evaluation of antimicrobial activity of different solvent extracts of medicinal plant: Melia azedarach L. International Journal of Current Pharmaceutical Research 4:67-73.

Sharma, D., and Paul, Y. 2013. Preliminary and pharmacological profile of Melia azedarach L.: An overview. Journal of Applied Pharmaceutical Science 3:133-138.

Shekari, M., Sendi, J.J., Etebari, K.,Zibaee,A., and Shadparvar,A. 2008. Effects of Artemisia annua L. (Asteracea) on nutritional physiology and enzyme activities of elm leaf beetle, Xanthogaleruca luteola Mull. (Coleoptera: Chrysomellidae). Pesticide Biochemistry and Physiology 91:66-74. doi:10.1016/j.pestbp.2008.01.003.

Silva, G., Rodríguez, J.C., Blanco, C.A., and Lagunes, A. 2013. Bioactivity of a water extract of boldus (Peumus boldus Molina) against Spodoptera frugiperda (J.E. Smith) and Helicoverpa zea Boddie (Lepidoptera: Noctuidae). Chilean Journal of Agricultural Research 73:14-15. doi:10.4067/s0718-58392013000200008.

Soudi, S., and Moharramipour, S. 2011. Cold tolerance and supercooling capacity in overwintering adults of elm leaf beetle Xanthogaleruca luteola (Coleoptera: Chrysomelidae). Environmental Entomology 40:1546-1553. doi:10.1603/en10267.

Vatanparast, M., Hosseininaveh, V., Ghadamyari, M., and Sajjadian, S.M. 2012. Pectinase and cellulase activity in the digestive system of the elm leaf beetle, Xanthogaleruca luteola Muller (Coleoptera: Chrysomelidae). Journal of Asia-Pacific Entomology 15:555-561. doi:10.1016/j.aspen.2012.05.017.

Verdeguer, M., García-Rellán, D., Boira, H., Pérez, E., Gandolfo, S., and Blázquez, M.A. 2011. Herbicidal activity of Peumus boldus and Drimys winterii essential oils from Chile. Molecules 16:403-411. doi:10.3390/molecules16010403.

Vogel, H., González, B., and Razmilic, I. 2011. Boldo (Peumus boldus) cultivated under different light conditions, soil humidity and plantation density. Industrial Crops and Products 34:1310-1312. doi:10.1016/j.indcrop.2010.10.039. 